\title{
Lightweight, Heavy Lifting: Knowledge Flows and Technology Transfer in a Materials Technology Lab
}

\author{
Peter Warrian \\ Munk School of Global Affairs, University of Toronto \\ Ahmed Najam \\ McMaster University
}

\section{WHY MIGHT IT BE IMPORTANT TO EXAMINE THE INTERACTION BETWEEN PUBLIC RESEARCH LABORATORIES AND SME FIRMS?}

The innovation systems approach highlights the manner in which the discovery and diffusion of new technologies is facilitated, or retarded, by the prevailing ensemble of social, economic and political institutions at different spatial scales and levels of industrial organization. Innovation and technical progress are increasingly generated by the complex set of structures that produce, distribute and apply various kinds of knowledge and combine that knowledge into new products. It emphasizes the relative importance of the patterns of interaction between firms as part of a collective learning process in the acquisition and use of new technical knowledge, and their interaction with the broader institutional elements of the overall system.

The key institutional feature affecting the success or failure of policies to promote technological upgrading are the effectiveness of interactive learning, within and between organizations and the capacity for risk taking. Studies of the macro-impact of funding basic research on innovation do not provide much insight into the precise mechanisms by which this knowledge is transferred (Wolfe, Goracinova \& Warrian 2016; Samford, Goracinova \& Warrian 2017; Wolfe 2017). The following article seeks to fill some of that gap.

\section{Innovation and Knowledge Transfer in the Automotive Supply Chain}

The divestment of auto parts production from OEMs was a major structural shift in the automotive industry. The cumulative impact has been to make the supply chain the major site of value added and innovation. In addition, the impact of enhanced environmental and safety regulations has resulted in "lightweighting" becoming the predominant driver in technological innovation in automotive manufacturing. The latter is a qualitative change where the mastery of microstructural manufacturing capability becomes a fault line between expanding margins and a downward spiral of cost-competitive competition. The technical merging of design and manufacturing changes what engineers do in the auto supply chain. (Smitka \& Warrian 2016; Helper \& Kuan 2016).

A mature automotive region like Ontario faces unique challenges. Its supply chain firms, particularly SMEs, tend of be in the lower end of the value chain and weakly represented in leading edge technologies like electronics and material science. The engineering culture of even the leading firms like Magna and 
Linamar, were built by their founders with an exclusive focus in identifying micro-efficiencies in parts production. This remains the DNA of the technical culture of the firms. It is inherently resistant to science revolution. When looking for positive examples elsewhere, Ontario faces the dilemma that all mature automotive regions confront: tightly integrated innovation systems like Baden Wurttemberg or the Midlands are much more successful but they face 'lock-in' issues that entrenches incrementalism. More de-centralized systems like the North American Automotive Alley, may be more open to radical technological change but are heavily dependent on the disparate capacities of SME firms. (Warrian 2015; Goracinova, Warrian \& Wolfe 2016).

Microstructural manufacturing challenges the divide between design and manufacturing. It also challenges the traditional boundaries between OEM firms and their supply chain partners. The entities outside the traditional boundaries include educational and research organizations not just Tier 1, Tier2 and Tier 3 suppliers.

The paper presents results of field research in the leading Canadian federal materials technology laboratory serving the auto industry. Some 31 automotive lightweighting projects were examined to better understand the dynamics of knowledge creation and technology transfer between the various parties. The conclusion is that changes in technologies allow "places" to open up for enhanced resiliency or reinvention for supply chain firms, if they take advantage of them. Otherwise they face the prospects of stagnation and failure.

\section{Enhanced Collaboration in the Supply Chain: The PACE Data}

As suppliers undertake a wider range of innovation and the role of car companies moves more toward that of a coordinator or integrator, SC firms need to be able to address the interdependencies of a vehicle as a system. In addition, innovations themselves frequently involve an array of mechanical and electronic features, and are contingent on developing new methods of manufacturing. Suppliers routinely form teams crossing firm boundaries to meet these challenges. These developments are reflected in the growth of recent PACE innovation awards for Collaboration.

The rise of systematic innovation and the decline of individual invention is also a key dynamic, whether internal to an existing supplier or in the form of an engineer working in their garage to develop an idea and then finding a parts supplier who will help commercialize it. An example of the latter is a new tire balancing system. While such examples continue to show up in the PACE process, for the past decade they have been infrequent. In contrast, what we see are companies that are repeat PACE finalists, such as Delphi, which through 2016 has had a representative on the award ceremony stage 62 times. The PACE data attempts to categorize innovations that came from a systematic innovation process, and those that furthermore were following a roadmap of where technology was going. Some are a reflection of external regulatory mandates like CAFE. Others, such as paints or adhesives, reflect product and process improvements that the industry has long sought, and where modern polymer chemistry and process controls are allowing improvements to finally be attained.

Suppliers face three core challenges. The first is the choice of where to direct their R\&D efforts. The second is how to coordinate those efforts with their suppliers and customers, as any single component is ultimately but one part of a complex assembled product. Third, they need to manage these efforts internally.

\section{Varieties of Coordination in Automotive Innovation}

Sergio Marchionne CEO of FCA has provocatively argued recently that the R\&D model of automotive innovation is bankrupting the car companies and undermining their enterprise value (Marchionne 2015). A new approach is needed. The core argument he makes is that auto industry with a product life cycle of 4 years to recoup their $R \& D$ costs is dramatically out of line with the 17 year product life cycle for other major manufacturing industries. His suggestion is that the car companies have to move beyond their current proprietary product platform strategy. 
Schulze, MacDuffie, and Taube (2015) also discuss knowledge generation and innovation diffusion in the global automotive industry. They focus on the central role of OEMs in system integration and their resulting dominance over product architecture and supply chain dynamics. However, new generations of software tools enable shifts in business models in the auto supply chain where traditional parts producers or contract manufacturers now offer "manufacturing capabilities" across the range of supply chain services, that is Research-Design-Manufacturing-Sales-Service-Recycling. Smaller- and lower-tier suppliers tend to employ only individual tools, but there are many specialized SME suppliers that use modules within PLCM platforms for their particular design, simulation, and costing needs.

As discussed in the introduction, we have had a 20 year trend of OEM disinvestment where more and more automotive manufacturing takes place in the supply chain, including greater R\&D responsibilities shifting to the supply chain firms. However, given that $90 \%$ of the supply chain in North America is comprised of SME firms, this raises the issue of the R\&D capacity of these firms. Field interviews suggest that perhaps $8-10 \%$ of SMEs currently have the internal capacity to do the requisite R\&D inhouse or with external partners.

For both of these reasons, the future of the auto industry is also linked to the capacities and functions of intermediate organizations (laboratories, universities, colleges, industry associations) to contribute to the innovation process in the auto supply chain.

\section{THE ROLE AND CONTRIBUTION OF A FEDERAL LAB}

\section{Applying the TRL Framework}

This section of the paper presents preliminary results of field research on a Federal laboratory ("the Lab") specializing in metallurgical technology and specifically its automotive research programme oriented to lightweighting. Project files on 31 research projects were examined, supplemented by personal interviews with Lab management, PIs and partner firms.

The analytical framework used is the application of Technology Readiness Levels (TRLs) which have become pervasive for research and funding agencies as criteria for successful funding applications, project management and evaluation. The automotive research programme at the Lab uses TRLs pervasively for prioritizing, managing and assessing their activities. ${ }^{1}$ The results examine the use of TRL scales to document and describe the specific mechanisms of knowledge creation and technology transfer between the different stages of the innovation process and the interaction between the Lab and its industry partners.

In summary, while social scientists have tended to use knowledge creation and technology transfer somewhat interchangeably, detailed examination of the cases reveals a much more nuanced story. What do each of the Technology Readiness Level steps (from 1 to 9) represent in terms of knowledge creation and technology transfer?

A project is at the first step of the TRL scale if no technological concept currently exists. Step 1 ensures that basic scientific principles are observed and are in the process of being converted into applied research and development. Reading scientific papers of a technology's basic properties are some of the activities that may occur at this step. There are no technology transfers or knowledge creation, but rather existing scientific knowledge is simply studied and observed. For example, \#26 is a project on Advanced High Strength Steels for Lightweight Vehicles, includes the three sub-projects: "Hydrogen Embrittlement", "Hot Stamping", and "Effect of S and N", was initially given a TRL rating of 1. That was because for each of the three sub-projects, while the scientific concepts had already existed, no technological concepts had yet been produced. At this stage the Lab observed and reported the relevant scientific concepts for each of the respective sub-projects, but there was no technology transfer or knowledge creation.

Stage 2 is reached once technology concepts and/or practical applications can be invented using the scientific concepts studied at Stage 1. There is no technology transfer at this stage, but there is knowledge creation. The knowledge creation at this stage could be a potential concept to develop a technology that helps to achieve the goals and objectives of the respective project. Some examples of this include the 
technological concept of an apparatus e.g. a new measuring device, or new rolling technology, or a new high pressure die casting process. In Project \#11 at TRL stage 2, the Lab developed a new rolling technology concept that could improve the texture and magnetic properties of electrical steels used for the core of the engine for electric vehicles. Also in \#26, in the "Hydrogen Embrittlement" sub-project, at TRL stage 2, the required apparatus and equipment were designed in order to conduct hydrogen charging.

At Stage 3, active research and development is initiated, including analytical and/or laboratory studies, and a proof of concept is defined. At this stage, there is knowledge creation but still no technology transfer. The knowledge creation at this stage is a result of actively conducting research, analytical, and/or laboratory studies to either measure, understand, and/or discover material properties, mathematical data, or performance metrics. An example of this is Project \#11, where at Stage 3 they conducted extensive laboratory rolling tests and measured the textures of the samples produced and validated that this rolling scheme did indeed optimize the textures and therefore significantly increased the potential efficiency of EV motors. The Lab further measured the magnetic properties of the processed samples and observed improvement of the magnetic quality. Another such example can be found in the Project \#27 on improvement of performance of high temperature cylinder heads, an alloy development sub-project, where extensive tests of mechanical properties were conducted using a variety of different alloys and their performance metrics were evaluated.

At Stage 4 of the TRL scale, components are validated in a laboratory environment and are integrated to establish that they work together. Lab environments differ from simulated environments as controls such as temperature and pressure tend to be more exact in lab environments. At this stage there is knowledge creation but usually no technology transfer. The knowledge creation may be from testing and validating technological components in a laboratory environment and assessing their performance/material properties such as strength, weight, thermo-mechanical fatigue, and machinability to see if they meet the requirements specified by the industrial partners. The knowledge creation is exemplified in Project \#1, where at stage 4 of the TRL scale, the Lab successfully joined multi-materials ( $\mathrm{Mg}$ to steel, Al to steel, steel to $\mathrm{Mg}$ ) using the refill friction stir spot welding (RFSSW) process in a laboratory environment and achieved the required strength at the weld joint. It can also be seen in Project \#9 on high-temperature stainless steel development, where they successfully validated samples of medium carbon steel in a laboratory environment to have improved material properties such as thermomechanical fatigue, machinability, and hot oxidation resistance.

Stage 5 of the TRL scale is similar to Stage 4, except that the components are to be validated in a simulated environment, rather than a laboratory condition. Simulated environments are a closer representation of the actual environments that the technology is to be employed in. Compared to previous stages, the Lab works more closely with the industrial partners at this stage in order to be able to validate the components in an appropriate simulated environment. There is knowledge creation, as well as technology transfer at this stage. The knowledge creation is largely the same as that of at stage 4 , but it is validated in a simulated environment instead. The technology transfer at this stage could be software, process control steps, process parameters, and/or material compositions, which have been validated in a simulated environment. In the Project \#9 case, stainless steel castings were cast and machined by the industrial partner, using the alloy composition developed by the Lab. The knowledge creation in this case came from conducting a series of evaluations at the industrial site, a simulated environment, to measure material properties such as the thermal cycle number to failure, oxidation resistance, the dimension measurements, and microstructure changes. The technology transfer here was the alloy composition for the medium carbon stainless steel that had now been validated in a simulated environment to meet the specified requirements.

At the Stage 6 of the TRL scale, a model or prototype representing a near desired configuration is tested in a simulated operational environment or a laboratory. At this point, there is always technology transfer and usually little to no new knowledge creation. The technology transfer at this stage is the result of validating a model or prototype in a simulated or laboratory environment. This is seen in Project \#9, where at stage 6, prototypes of Y-tube stainless steel castings for engine exhaust simulator testing were produced and tested in a simulated environment at an industrial site. Similarly, in Project \#33 on new 
aluminum alloys for high pressure die casting, prototypes for the rear end cross member were produced using an actual die supplied by an auto OEM and were then tested in the laboratory environment, to evaluate the tensile and fatigue properties of the aluminum alloys and verify that they meet the operational requirements. The technology transfer here came from being able to validate an actual prototype that represented a near desired configuration in a laboratory environment.

At Stage 7 of the TRL scale, a prototype is ready for demonstration in an operational environment. Some activities at this stage may include prototype field testing. As in the previous stage, there will be technology transfer but usually no new knowledge creation at this point. The transfer of technology here is a near final product that is ready to be demonstrated in an appropriate operational environment. As seen in Project \#9 project, at the $7^{\text {th }}$ stage of the TRL scale, the industrial partner performed actual design verification on the Y-tube stainless steel castings, an important stage in the process leading up to a product launch. The technology transfer at this stage is a prototype that has been demonstrated in an appropriate operational environment and is now ready for design tests.

Stage 8 is similar to Stage 7, in that they both deal with design verification. During Stage 8, it has been proven that the developed technology will work in its final form and under expected conditions. By the end of Stage 8, the actual technology should be completed and qualified for all tests and demonstrations, and be evaluated to see whether it will meet operational requirements. There is no knowledge creation, the technology transfer at this stage would be the actual technology completed and qualified through tests and demonstrations.

Finally, at Stage 9 of the TRL scale, the final product validation takes place, typically nine months before the product launch. The actual application of the technology is in its final form and under real-life conditions. There is no knowledge creation but there is technology transfer in the form of actual technology being proven through successful deployment in an operational setting.

The Lab is not currently authorized to proceed with TRL 8 \&9 projects, so while management is well informed about these Steps, there were no current projects. The contribution of the Lab to commercialization is limited to the range of TRLs 4-7.

\section{CASE STUDIES OF PROJECT DYNAMICS}

Examination down to the individual project level gives further granularity to the analysis and gives a detailed account of the dynamic interaction and iterative nature of the relationship between the Lab and its industrial partners.

\section{Project 8: Tier 1 Parts Maker}

There has been a long relationship between the Lab and a major aluminum producer. In fact, the PI on the project previously worked there. The producer supplied materials to Tier 1 parts manufacturers.

Increased fuel efficiency is associated with higher temperatures of exhaust gases. New engines and turbo chargers are generating high temperatures and the demands on heat exchangers escalate. Existing heat exchangers are made of old materials with limits to the temperatures they can withstand. The new fuel standards and turbo chargers changed things. The shift to new materials required a shift in the alloy mix.

Meetings took place between 2008-2012 in a previous project when the aluminum producer was the lead client. However, the aluminum company's whole R\&D centre moved to the US after a takeover. Only the parts manufacturer was still working on R\&D.

The technical development was done at the Lab. However they needed input material and relied on a small firm left at the original production site run by employees who didn't want to go to the USA and were using casting equipment that could not be moved. They cast the new chemical compositions into ingots.

The testing was two-fold: The Lab did the mechanical testing. The manufacturer did corrosion resistance testing. The lab does the underlying chemical composition and creates a "product". The parts manufacturer produces the final product and feeds back test results to the lab to adjust the composition. 
The project revealed an important shift, not only in the business model of the Lab but more importantly in its position within the value chain. This was an important shift for the Lab. Their traditional partners were the materials producers who had deep materials metallurgy capacity, well within the basic science range of TRls 1-3. As they have shifted to commercialization and TRL 4-7, the manufacturer or User of the material became the Lab's client. The new material input can be produced by any $\mathrm{Al}$ producer.

\section{Project 33: Automotive OEM}

An auto OEM is interested in structural $\mathrm{Al}$ alloys using high pressure die casting. The car company is good at coatings but poor on dies. Aluminum likes to eat steel, so putting it into a steel die means the material will stick and degrades very expensive dies. The OEM was looking for alternative alloy recipes.

In an un-related field, an outboard marine engine producer, identified by the Lab, had exactly such an alloy and had the IP on it. In the project the car company gave the Lab its dies and the outboard engine manufacturer gave them the alloys for the Lab to do validation testing. Casting of this type is quite complicated so OEM personnel came to the Lab to do the set up. The Lab did a run of 100 castings to monitor the wear on the dies. A further pre-production 20k run was done by the OEM to validate the material and integrate it into their "Material Car" which is the inventory of validated solutions that their design engineers are allowed to use. Ultimately, the work of the Lab was to feed the design process.

There is now a Phase 2 of this project in the new 5-year research programme at the Lab.

\section{Project 35: Specialized Tier 2 Parts Maker}

The company is a Tier 2 specialized Canadian producer of Magnesium parts with two plants in Canada and 7 more in Europe and Asia. Magnesium was once a major part of the Lab's materials programme but as primary $\mathrm{Mg}$ production is no longer taking place in Canada, their expertise was orphaned.

Originally the partner company was part of a European producer but a series of takeovers and buyouts changed their mandate. They eventually re-organized and were mandated to get into Al casting. The casting equipment could theoretically do both $\mathrm{Mg}$ and $\mathrm{Al}$ inputs but the processes are different, it is continuous, and can't be batched.

The company came to The Lab to learn how to learn the aluminum processing business. The Lab were supplied with the dies and developed the appropriate aluminum alloys. It was a technology transfer from $\mathrm{Mg}$ to $\mathrm{Al}$ within the company but with the Lab it was exclusively a knowledge exchange. However, no Al production casting was ever done. The company was sold to the Chinese who brought in a Chinese Magnesium producer. Production continues but only on the $\mathrm{Mg}$ side.

Meanwhile a leading Parts OEM is now interested in Al casting. They are send designs to The Lab to assess its manufacturability. It is technology and knowledge transfer.

\section{Project 4: Specialized Tier 2 Parts Maker}

The client company does advanced hydroforming. This is a project addressing a pervasive problem of manufacturing with advanced lightweight materials i.e. the Springback Problem. The new materials are so strong that conventional stamping and forming technology results in below grade products because the material springs back from its full forming design due to the resistance in the material. The problem will only get worse as materials progress in getting stronger and lighter.

It is also a project that bridges manufacturing and design. Their solution ultimately impacts the design process because of the ability to predict springback and therefore better able to predict the final shape of the product.

In this case linkage to another government lab, at a nuclear reactor facility, became critical. The nuclear site was used for a specialized testing capacity employing the reactor's neutron beam to test for residual tension in the input materials. 
The modelling software for materials and product design are critical. Both parties used different software platforms but the Lab worked out a new set of processing parameters and then did a translation to the company's system.

While they were working on the springback problem, the Lab discovered that there was also embedded tension in the input material that came from the supplier steel company. With data from the reactor, they built a model of the actual rolling process of the tubes at the steel mill, assisted by production data from the mill. It was discovered that the steel tubes and the welding process were the source of the problem.

The Lab built a model of the whole steel mill to model the stresses in the rolling process. This in turn fed into the manufacturer's design process. They also built a simulation translator that meant that they did not have to test dies by trial and error. They could predict changes. Bending and forming turned out to be two separate springback challenges.

However, the client company is too small to serve as a project partner by themselves. They are always having financial and technical personnel restraints. Work continues with the steel company. The case illustrates the challenge for SME firms in taking on R\&D and design responsibilities in the auto supply chain.

\section{Project 9: Specialized Tier 2 Parts Maker}

This is a project with a specialized Tier 2 casting producer. The PI at the client worked at the company previously on design and experiments involving microgravity, mechanical materials and alloys. The partner company already had ties to The Lab when it was in a previous location. Their business is iron casting and steel casting, supplying all the OEMs with exhaust components.

The PI's interest is in manufacturability of stainless steels and it was he who developed the concept and solution and took it to the industry partner. High temperature engines put materials in question. Iron melts at $1100 \mathrm{C}$, steel at 1300-1400. To keep up with the combustion temperature increases, the company had to look at leaving iron behind and going to stainless steel for heat exhaust parts. They still do iron casting but their future growth will be in steel.

The PI came up with the idea that there would be manufacturing advantages if they could move from high carbon to mid-carbon steel which has better machinability. He came up with the idea and knew about manufacturing processing from his previous experience at the company. He contacted his old boss and that evolved into the industrial partnership. The Lab did the basic technology and produced the samples. They provided the processing parameters and the company cast the prototypes. The Lab also produced the material inputs. On the machining side, The Lab sent the bars for machining tests to a machining lab at the university. The key is milling smooth surfaces.

The Lab's contributions were the chemical composition for the product and processing data for manufacturability. Feedback comes later from the company as they interact with their customers. They move from The Lab's formulations to their own internal specifications which are closely guarded. The range of alloy mixes are different between OEMs: initially $03 .-0.5 \%$ then 0.1 to $0.3 \%$. They then iterate the results back to the Lab for testing. This determines grades in internal documents.

Phase 2 of the project is working on issues related to lightweighting, thin wall products and the processing challenges.

\section{Project 27: Automotive OEM}

This is a project about alloy development for design of cylinder heads that can withstand higher heat and greater torque. The auto OEM has in-house alloy development capacity in Michigan and at Ontario. The technical issue is that $\mathrm{Al}$ has a low melt point, but can be combined with transition metal alloys: $\mathrm{Ti}$, $\mathrm{Zn}, \mathrm{Va}$.

The basic alloy mix has been under development by the OEM since 2008. The Lab produced a different recipe that was better performing than the best of the OEM recipes. A major aluminum producer, supplying the OEM, also came out with a similar alloy product and eventually they came in as a project 
partner. In fact, the aluminum producer has now by itself come on as an industrial partner with the Lab on the next generation of alloys. It is a 5 year project with joint government and industry funding.

Alloy development is critical to the manufacturing process of high pressure casting. The challenge is to do casting that also includes internal shapes. The external geometry is done through the casting processes. But the internal geometry requires a core to be inserted then either dissolved or removed. The core has to be strong enough to withstand the casting pressure but be weak enough to be removed later.

The Lab had the hardware, casting machinery and the processing experience to do both stages of the process. It was not clear if the OEM had the capacity or the time. It is very complex and took four years of testing and iteration to get it right. The processing issues include casting hot metal at $60 \mathrm{ft}$. per min with the required processing scope. They are trying to do it all within the capabilities of existing equipment. The core may be different, as well as configuration and protection. The IP issues include both the geometry and the chemistry.

The outcome in the Lab was that they cast 20 parts with acceptable dimensions and quality. It is now up to the OEM to carry it through to final commercialization.

\section{THE INNOVATION STORY VS THE TECHNOLOGY TRANSFER STORY}

The above cases, in the author's view, outline a persuasive innovation story. There still remains the challenge of telling the technology transfer story i.e. what are the specific stages and mechanisms of the technology transfer. To better understand the underlying dynamics, we went deeper on Case \#9.

The initial idea of a change of materials from aluminum to stainless steel because of the high temperatures coming from high efficiency engines, came from a researcher at the Lab who was a former employee of the client company.

Step 1 was for research scientists at the Lab to produce a new Sparse Matrix of the proposed material recipe comprising the alloy mix on one axis and characterization of the material properties on the other.

After exchanges with the firm and agreement on the initial mix, the parties worked together at Step 2 to produce an Intermediate Matrix comprising the material properties on the one axis and the processing parameters on the other. To produce the new matrix, the company applies a genetic algorithm they have generated with the assistance of the computational group at the Lab. It is an iterative process that produces a Matrix that the firm feels confident enough to begin showing to their customers.

Step 3 is the interaction between the firm and its client (OEM or Tier 1) to refine the Final Matrix to where the Material Properties and Processing Parameters are tested by trial and error to a level that the customer is confident that they can go to the market place with the final product. The threshold decision is a risk assessment of the product, processing and alloy mix together.

\section{Policy Co-ordination and the Cognitive Capacities of SME Firms}

Automotive clusters considered to be revitalized, such as those in the West Midlands of the U.K. or Detroit, are characterized by: support for projects in the range of technology readiness levels spanning concept to market, which is also accessible to a significant portion of automotive SMEs. This is both because initiatives explicitly aim to support firms in the low value- added segments of the industry (e.g. SMMT Industry Forum), but also because of the heavier presence of technology intensive suppliers. This tendency has aided in cluster renewal, characterized by a growing segment of SMEs involved in all stages of the design and innovation process and, in particular, through the emergence of automotive engineering services clusters.

A point of difference between technological intermediaries in Canada, as compared to those in Germany, is that they are often initiated by civil society actors, as is the case with the community colleges, which apply for government funds in an effort to bring SMEs closer to emerging enabling technologies. Although there is greater reliance on public-private partnerships in recent initiatives, the Canadian case does not necessarily demonstrate greater coordination among initiatives or longer term financing. They have been decentralized and not part of a coherent technological roadmap or automotive strategy. Future study would delve into the precise reasons for the differences in coordinating 
arrangements and the degree of their impact on the ability of automotive regions to break away from incremental innovation strategies, if the goal is to do so.

However the results are uneven. Interviews by Warrian and others hint at cultural factors limiting SME development in these new directions. Many SME founders and innovators found success as handson managers delivering manufacturing micro efficiencies. They scaled their businesses and achieved career progression based on sweating details such as the cost of drills and other consumables. Software simulations and systems level gains are not in their DNA.

By contrast, an Ontario-based 2015 PACE manufacturing innovation finalist was a sheet hydroformed clamshell liftgate for a Ford Lincoln SUV. Normal manufacturing for such a deeply curved piece would require two stampings that would be welded together. They were able to turn it out as a single continuous piece. Close collaboration between the company and the OEM's design engineers was essential. OEM engineers have computer models for standard stamping technology, but they are not adapted for the different metal flow characteristics of low-pressure sheet hydroforming. The supplier had developed such models and was able to convince the OEM that they were accurate and, with the normal sorts of modifications for angles and relief cuts, could turn out the liftgate that their SUV stylists wanted. The ability to provide design capabilities using their own, proprietary software was key to the project's success.

The company continues to engage in advanced development work on other metal-forming processes. One example is "Dieless NC Forming." At a conceptual level this uses the millennia-old process of hammering sheet metal against an anvil to form complicated shapes without needing a die. In practice, they use a rotating stylus on top and a small-diameter fixture below. This process uses numerically controlled machinery and so can go directly from a CAD drawing to their forming machine.

Another example. There has been a decade's long decline in the Windsor plastics injection molding industry for auto parts. Chinese manufacturers took over with re-purchased or stolen die designs, with the result that domestic companies lost their tacit "feel" for the machining process with the materials themselves. The new digital tools are allowing mold firms to re-engage with the materials. A company who has re-emerged as a leader in the local industry did it by making a detour into another industry in order to further develop the technology. Bottling companies are under as much pressure as the auto companies in regard to environmental regulations. Lightweighting is imperative there as well. The tipping point was that there is a key engineering ratio of wall thickness to the height of the bottle. If the ratio is greater than 1:200 an error in the injection die of 0.001 inches can cause the collapse of the container. With the latest German machines the company showed bottlers that they could maintain that level of precision for their molds. This led to a contract with the largest coke bottle maker in the United States located in Toledo, a short drive away. These are also the tolerances needed for the high-precision dies used in aerospace. The firm is now pitching their services to the Canadian companies in that sector, which are based in Montreal. Rather than trying to expand to become a global automotive supplier, the firm is using their ability to interact with customers to meet specialized needs to move horizontally along the value chain as well as into another vertical.

Automotive researchers such as MacDuffie suggest that there will be innovative new players coming into the auto supply chain from the permeable boundary with related industries and technologies. The moldmaker story suggests that there will also be movement of innovative suppliers out of the auto industry.

The case studies in this section reflect the transformation of the supply chain and its implications for the locus of vehicle engineering. As the injection molding supplier case indicates, not all suppliers of technology find it profitable to exclusively remain in the industry, while SMEs such as the liftgate producer find it hard to break into what is now a global industry. The ability of steel companies such as ArcelorMittal, as well as their rivals in aluminum such as Novelis, to move from manufacturing into design has been more successful. Nevertheless, they are constrained by the product and platform architectures of the OEMs, which under a "platform" strategy use carryover parts and adaptations to previous designs rather than a "clean sheet" approach. 
Innovation studies academics see these developments as an important lesson in the new global economy where the new digital technologies contribute to a mobility of production functions along global value chains. New business models arise as firms move forward, backwards, and sideways.

\section{THE AUTOMOTIVE POLICY CHALLENGE: MAKING DIFFERENT BETS}

The southern Ontario automotive cluster faces a complex set of innovation challenges, with the majority of automotive R\&D performed abroad by resident Original Equipment Manufacturers (OEMs) and intensified competition for investment from other North American jurisdictions. To improve the competitiveness of the sector, policies adopted in the wake of the 2008-09 financial and automotive crisis directed increased support towards more applied research through both industry-specific initiatives, such as the Automotive Innovation Fund, and collaborative research efforts into enabling technologies to promote more sustainable production operations. Simultaneously, there have been several private sectorled initiatives to reinvigorate segments of the automotive supply chain.

These policy shifts in Ontario and other jurisdictions are occurring in a context where intensified international competition and cost pressures have combined with stricter CAFÉ environmental regulations and consumer safety standards to drive innovation further down the automotive supply chain. The range of technologies that are important to success in the industry has expanded - from electronics, to digital platforms, new fuel and power technologies, and light weighting materials. The need for more systemic innovations has led to a process of increasingly 'open' innovation (Chesbrough 2003), shifting the locus of innovation from within a single firm, the OEM, to a wider range of firms along the supply chain, research institutes and end-users (Köhler et al. 2012). The critical challenge concerns the ability of firms located at various stages along the automotive supply chain in Ontario to adapt to this shifting locus of innovation.

Network failures have been identified as a reason for the lock-in of old industrial regions in mature technological trajectories. Recently policy-makers, civil society and private sector actors, have begun to support the introduction of more associative arrangements in traditionally non-coordinated economies, such as the US, UK and Canada. These collaborative projects often lie at the higher end of the TRL's scale (4-7), strongly oriented to near-term commercialization in assisting companies to move toward widespread technology adoption. Nonetheless, there are noticeable variations in how these coordination arrangements have emerged in various institutional settings among the competitor regions, which is missing from national level studies of evolving industrial policies. As the evidence from research presented in this article suggests, these associative arrangements differ among various regions in Europe and North America depending on the role played by public and private sector actors and existing structural and institutional constraints, meaning that emergent forms of coordination are not fully defined by their national context.

The primary difference, although not necessarily the most important one, is between those policy mixes that continue to exclude SMEs from greater involvement with intermediary institutions that support innovation along the automotive supply chain and those which facilitate their increased inclusion in evolving knowledge networks. The difference is particularly evident when comparing the portion of the automotive supply chain that has access to innovation resources in the regional research infrastructure of universities, government laboratories and formal partner networks that are vital to the commercialization and diffusion of new technologies. Although we do not claim that these coordinating arrangements are the primary causal factor behind the renewal of the different automotive regions, they do appear to be an important element in their reinvigoration. A significant risk to the economic future of southern Ontario's automotive cluster is that the vast majority of SME firms in the automotive supply chain will not access the innovation assistance or shared public goods that they need for the future.

Variations in who benefits from these initiatives are relevant because it is the presence of SMEinclusive networks, whether privately or publicly-led, which are important to regions where the automotive sector has recovered and is thriving. In other words, Ontario might draw lessons from ongoing developments in competitor jurisdictions to overcome the obstacles described above in adopting new 
forms of networked arrangements to support innovation. Despite the presence of collaborative projects that support companies in the later stages of the innovation process, our evidence suggests that these remain largely inaccessible for the vast portion of automotive SMEs in southern Ontario. Interviewees indicate that only about 8-10 per cent of SMEs are able to meaningfully engage with universities or government labs. This is because automotive suppliers are concentrated in the low value-added segments of the industry and lack the absorptive capacity to benefit from the new cluster resources.

The on-going interactive knowledge exchange between public research labs and SME firms is a central forum for increasing the cognitive capacity of SME firms and, ultimately the sustainability of the Canadian automotive supply chain.

\section{ENDNOTES}

1. See Government of Canada Technology Readiness Levels Scale in Appendix 1.1

\section{REFERENCES}

Chesbrough, H. Open Innovation. 2003. Boston. Harvard Business School Press.

Goracinova, Warrian \& Wolfe. 2017. "Challenges of Coordination: Automotive Innovation in the Ontario Supply Chain in Comparative Context”, Canadian Public Policy (Forthcoming Spring 2017)

Helper, S. and Kuan, J. (2016) "What Goes Under the Hood? How Engineers Innovate in the Automotive Supply Chain." In Freeman, Richard \& Salzman, Hal, eds. Engineering in a Global Economy. Chicago: University of Chicago Press.

Köhler, C., Laredo, P. and Rammer, M. 2012. The Impact and Effectiveness of Fiscal Incentives for R\&D. Compendium of Evidence on the Effectiveness of Innovation Policy Intervention Project. Manchester, U.K. Manchester Institute for Innovation Research, University of Manchester.

Marchionne, S. "Confessions of a Capital Junky", Presentation to Financial Analysts. November 2015.

Samford, Goracinova \& Warrian 2017. "Public and private goods in the development of additive manufacturing capacity". Business and Politics, April 2017.

Schulze, A., MacDuffie, J. \& Taube, F.. (2015) "Introduction: knowledge generation and innovation diffusion in the global automotive industry--change and stability during turbulent times." Industrial and Corporate Change 24, no. 3, pp. 603-611.

Smitka, M. and Warrian, P. A Profile of the Global Auto Industry: Innovation and Dynamics, BEP Press (2016).

Warrian, P and Smitka, M. 2015. "The Changing Dynamics of Innovation in the Auto Supply Chain", Journal of Business and Economics, Vol. 6, No. 4, April 2016.

Wolfe, D. 2017. "Impact and Effectiveness of Public Support for Business Innovation". Mimeo. Innovation Policy Lab, University of Toronto, October 2017. 


\section{APPENDIX 1 \\ Technology Readiness Levels}

\begin{tabular}{|c|c|}
\hline TRL Level & Description \\
\hline $\begin{array}{l}\text { 1. Basic principles observed } \\
\text { and reported. }\end{array}$ & $\begin{array}{l}\text { Lowest level of technology readiness. Scientific research begins to be } \\
\text { translated into applied research and development. Example might include } \\
\text { paper studies of a technology's basic properties. }\end{array}$ \\
\hline $\begin{array}{l}\text { 2. Technology concept } \\
\text { and/or application } \\
\text { formulated. }\end{array}$ & $\begin{array}{l}\text { Invention begins. Once basic principles are observed, practical } \\
\text { applications can be invented. The application is speculative and there is no } \\
\text { proof or detailed analysis to support the assumption. Examples are still } \\
\text { limited to paper studies. }\end{array}$ \\
\hline $\begin{array}{l}\text { 3. Analytical and } \\
\text { experimental critical } \\
\text { function and/or } \\
\text { characteristic proof of } \\
\text { concept. }\end{array}$ & $\begin{array}{l}\text { Active research and development is initiated. This includes analytical } \\
\text { studies and laboratory studies to physically validate analytical predictions } \\
\text { of separate elements of the technology. Examples include components that } \\
\text { are not yet integrated or representative. }\end{array}$ \\
\hline $\begin{array}{l}\text { 4. Component and/or } \\
\text { breadboard validation in } \\
\text { laboratory environment. }\end{array}$ & $\begin{array}{l}\text { Basic technological components are integrated to establish that the pieces } \\
\text { will work together. This is "low fidelity" compared to the eventual system. } \\
\text { Examples include integration of 'ad hoc' hardware in a laboratory. }\end{array}$ \\
\hline $\begin{array}{l}\text { 5. Component and/or } \\
\text { breadboard validation in } \\
\text { relevant environment. }\end{array}$ & $\begin{array}{l}\text { Fidelity of breadboard technology increases significantly. The basic } \\
\text { technological components are integrated with reasonably realistic } \\
\text { supporting elements so that the technology can be tested in a simulated } \\
\text { environment. Examples include 'high fidelity' laboratory integration of } \\
\text { components. }\end{array}$ \\
\hline $\begin{array}{l}\text { 6. System/subsystem model } \\
\text { or prototype demonstration } \\
\text { in a relevant environment }\end{array}$ & $\begin{array}{l}\text { Representative model or prototype system, which is well beyond the } \\
\text { breadboard tested for TRL 5, is tested in a relevant environment. } \\
\text { Represents a major step up in a technology's demonstrated readiness. } \\
\text { Examples include testing a prototype in a high fidelity laboratory } \\
\text { environment or in simulated operational environment. }\end{array}$ \\
\hline $\begin{array}{l}\text { 7. System prototype } \\
\text { demonstration in an } \\
\text { operational environment }\end{array}$ & $\begin{array}{l}\text { Prototype near or at planned operational system. Represents a major step } \\
\text { up from TRL } 6 \text {, requiring the demonstration of an actual system prototype } \\
\text { in an operational environment, such as in an aircraft, vehicle or space. } \\
\text { Examples include testing the prototype in a test bed aircraft. }\end{array}$ \\
\hline $\begin{array}{l}\text { 8. Actual system completed } \\
\text { and 'flight qualified' through } \\
\text { test and demonstration }\end{array}$ & $\begin{array}{l}\text { Technology has been proven to work in its final form and under expected } \\
\text { conditions. In almost all cases, this TRL represents the end of true system } \\
\text { development. Examples include developmental test and evaluation of the } \\
\text { system in its intended weapon system to determine if it meets design } \\
\text { specifications. }\end{array}$ \\
\hline $\begin{array}{l}\text { 9. Actual system 'flight } \\
\text { proven' through successful } \\
\text { mission operations }\end{array}$ & $\begin{array}{l}\text { Actual application of the technology in its final form and under mission } \\
\text { conditions, such as those encountered in operational test and evaluation. In } \\
\text { almost all cases, this is the end of the last "bug fixing" aspects of true } \\
\text { system development. Examples include using the system under } \\
\text { operational mission conditions. }\end{array}$ \\
\hline
\end{tabular}

Source: https://buyandsell.gc.ca/initiatives-and-programs/build-in-canada-innovation-programbcip/program-specifics/technology-readiness-level 